\title{
O MEC E A REORGANIZAÇÃO CURRICULAR
}

Iara Glória Areias Prado

Secretária de Educação Fundamental do MEC

\begin{abstract}
Resumo: O texto apresenta um resumo sobre o movimento de reorganização curricular promovido pela Secretaria de Educação Fundamental do Ministério da Educação do Brasil e aborda os seguintes temas, entre outros: organização da educação básica; questão curricular e qualidade da educação; Parâmetros Curriculares Nacionais; referências curriculares e concepções norteadoras; e formação de professores.

Palavras-chave: educação e realidade brasileira; desenvolvimento curricular e instituição pública.
\end{abstract}

A Educação Básica no Brasil é composta por três etapas: educação infantil (que atende hoje cerca de 5 milhões de crianças de 0 a 6 anos, em creches ou pré-escolas, geralmente mantidas pelo poder municipal); ensino fundamental (que atende cerca de 36 milhões de alunos de 7 a 14 anos, tem caráter obrigatório, é público, gratuito e oferecido de forma compartilhada pelos poderes municipal e estadual) e ensino médio (que atende cerca de 7 milhões de jovens de 15 a 17 anos e é oferecido basicamente pelo poder estadual).

No Brasil, existe um contingente ainda expressivo, embora decrescente, de jovens e adultos com pouca ou nenhuma escolaridade, o que faz da Educação de Jovens e Adultos um programa especial que visa dar oportunidades educacionais apropriadas aos brasileiros que não tiveram acesso ao ensino fundamental na idade própria, cujo atendimento representa, aproximadamente, 3 milhões de alunos.

No que se refere às comunidades indígenas, a Constituição garante-lhes o direito de utilizar suas línguas maternas e processos próprios de aprendizagem, o que se justifica pela existência de cerca de 1.600 escolas indígenas, que hoje possuem cerca de 80 mil alunos índios.

Apesar do grandioso número de alunos - mais de 50 milhões - o grande desafio da educação brasileira, que está sendo enfrentado hoje, não é mais a oferta de vagas, mas sim a necessidade de construir escolas onde se aprenda mais e melhor.
Relativamente à questão curricular e à qualidade da educação, pode-se dizer que currículos compreendem a expressão dos conhecimentos e valores que uma sociedade considera que devem fazer parte do percurso educativo de suas crianças e jovens. Eles são traduzidos nos objetivos que se deseja atingir, nos conteúdos considerados os mais adequados para promovê-los, nas metodologias adotadas e nas formas de avaliar o trabalho desenvolvido. A definição de quais são esses conhecimentos e valores vem sendo modificada nos últimos anos, devido às demandas criadas pelas transformações na organização da produção e do trabalho e pela conjuntura de redemocratização do país. Portanto, a meta de melhoria da qualidade da educação impôs o enfrentamento da questão curricular como aquilo que deve nortear as ações das escolas, dando vida e significado ao seu projeto educativo.

É importante considerar também que, no quadro de diversidade da realidade brasileira, existem grandes discrepâncias em relação à possibilidade de se ter acesso aos centros de produção de conhecimento, tanto das áreas curriculares quanto da área pedagógica. Isto é refletido na formação de professores e nos currículos das escolas, o que não favorece a existência de uma eqüidade na qualidade da oferta de ensino das cerca de 250.000 escolas públicas brasileiras dispersas nas cinco regiões do país. 
Até 1995, não havia no país uma referência nacional para nortear os currículos propostos pelas 27 secretarias de educação estaduais e 5.600 municipais que compõem o Estado federativo brasileiro. Após um longo processo de debate nacional, foi aprovada, em dezembro de 1996, a Lei de Diretrizes e Bases da Educação Nacional - lei máxima da educação brasileira -, que, dentre suas propostas, determina como competência da União estabelecer, em colaboração com estados e municípios, diretrizes para nortear os currículos, de modo a assegurar uma formação básica comum em todo o país.

Era preciso portanto construir referências nacionais para impulsionar mudanças na formação dos alunos, no sentido de enfrentar antigos problemas da educação brasileira e os novos desafios colocados pela conjuntura mundial e pelas novas características da sociedade - como a urbanização crescente. Por outro lado, essas referências precisavam indicar pontos comuns do processo educativo em todas as regiões e, ao mesmo tempo, respeitar as diversidades regionais, culturais e políticas existentes.

Dessa forma, no primeiro mandato do presidente Fernando Henrique Cardoso, uma das prioridades do Ministério da Educação foi a elaboração de referências curriculares para a educação básica, um processo inédito na história da educação brasileira, sistematizando idéias que já vinham sendo utilizadas nas reformulações curriculares de estados e municípios.

Os procedimentos seguidos na elaboração dos documentos representam a manifestação do espírito democrático e participativo que deve caracterizar a educação de base no país. Equipes de educadores (professores com larga e boa experiência nas salas de aula, professores universitários e pesquisadores) elaboraram os documentos preliminares. Estas equipes realizaram um estudo dos currículos de outros países (como Inglaterra, França, Espanha, Estados Unidos), analisaram as propostas dos estados e de alguns dos municípios brasileiros, considerando os indicadores da educação no Brasil (como taxas de evasão e repetência, desempenho dos alunos nas avaliações sistêmicas) e estudaram os marcos teóricos contemporâneos sobre currículo, ensino, aprendizagem e avaliação.

Os documentos preliminares foram enviados para apreciação e receberam críticas e sugestões de professores universitários e de sala de aula, pesquisadores e de técnicos que atuam nas equipes pedagógicas das secretarias de educação, tendo como idéia-força a perspectiva da formação para a cidadania, pois a criança não é só a cidadã do futuro, ela já é cidadã. Essas idéias inovam ao ins- tituir o que se pode chamar de "escola-cidadã", expressão de uma política educacional fortemente marcada pelo empenho de criar novos laços entre ensino e sociedade.

A finalidade das referências curriculares consiste na radical transformação dos objetivos, dos conteúdos e da didática na educação infantil, no ensino fundamental e na educação de jovens e adultos. Os conteúdos estudados passam a ser os meios com os quais o estudante desenvolve capacidades intelectuais, afetivas, motoras, tendo em vista as demandas do mundo em que vive. A formação se sobrepõe à informação pura e simples, modificando o antigo conceito de que educação é somente transmissão de conhecimentos.

A concepção pedagógica subjacente, na nova proposta curricular, aponta no sentido de que:

- a escola existe, antes de tudo, para os alunos aprenderem o que não podem aprender sem ela;

- o professor organiza a aprendizagem, avalia os resultados, incentiva a cooperação, estimula a autonomia e o senso de responsabilidade dos estudantes;

- nada substitui a atuação do próprio aluno no processo de aprendizagem;

- o ponto de partida é sempre o conhecimento prévio do aluno;

- a avaliação é um instrumento de melhoria do ensino e não uma arma contra o aluno;

- a aprendizagem bem-sucedida promove a auto-estima do aluno; o fracasso ameaça o aprender e é o primeiro passo para o desinteresse.

A nova proposta apresentada pelo Ministério da Educação aos educadores brasileiros é composta dos documentos Parâmetros Curriculares Nacionais para Educação Fundamental, Referencial Curricular Nacional para a Educação Infantil e para Educação Indígena e a Proposta Curricular para Educação de Jovens e Adultos.

Dentro das propostas já referidas, cada qual com sua especificidade, os Parâmetros Curriculares Nacionais para o Ensino Fundamental incluem, além das áreas curriculares clássicas (Língua Portuguesa, Matemática, Ciências Naturais, História, Geografia, Arte, Educação Física e Línguas Estrangeiras), o tratamento de questões da sociedade brasileira, como aquelas ligadas a Ética, Meio Ambiente, Orientação Sexual, Pluralidade Cultural, Saúde, Trabalho e Consumo, ou outros temas que se mostrem relevantes.

Considerando as particularidades da faixa etária compreendida entre 0 e 6 anos, a proposta educativa dos refe- 
DIAGRAMA 1

Conteúdos Curriculares

\begin{tabular}{|c|c|c|}
\hline $\begin{array}{c}\text { Referencial Curricular Nacional para } \\
\text { Educação Infantil - } \mathbf{0} \text { a } \mathbf{6} \text { anos }\end{array}$ \\
\hline $\begin{array}{c}\text { Formação Pessoal e } \\
\text { Social }\end{array}$ & $\begin{array}{c}\text { Conhecimento de } \\
\text { Mundo }\end{array}$ \\
\hline $\begin{array}{c}\text { Identidade e } \\
\text { Autonomia }\end{array}$ & $\begin{array}{c}\text { Movimento - Artes Visuais - Música - Linguagem } \\
\text { Oral e Escrita - Natureza e Sociedade - Matemática }\end{array}$ \\
\hline
\end{tabular}

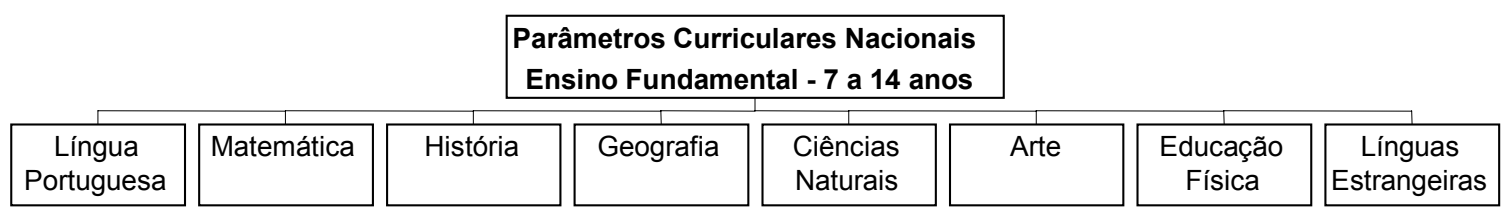

Ética, Saúde, Meio Ambiente, Orientação Sexual, Pluralidade Cultural, Trabalho e Consumo

\begin{tabular}{|c|c|c|c|c|c|c|}
\hline \multirow[b]{2}{*}{$\begin{array}{l}\text { Língua } \\
\text { Portuguesa }\end{array}$} & \multirow[b]{2}{*}{ Matemática } & \multicolumn{3}{|c|}{$\begin{array}{l}\text { Referencial Curricular Nacional } \\
\text { para as Escolas Indígenas }\end{array}$} & \multirow[b]{2}{*}{ Arte } & \multirow[b]{2}{*}{$\begin{array}{l}\text { Educação } \\
\text { Física }\end{array}$} \\
\hline & & História & Geografia & $\begin{array}{l}\text { Ciências } \\
\text { Naturais }\end{array}$ & & \\
\hline & $\begin{array}{l}\text { ustentação } \\
\text { rra e Prese }\end{array}$ & $\begin{array}{l}\text { a Indíge } \\
\text { a da Bic }\end{array}$ & $\begin{array}{l}\text { uralidade } \\
\text { sidade e }\end{array}$ & $\begin{array}{l}\text { al, Direi } \\
\text { ção Pre }\end{array}$ & $\begin{array}{l}\mathrm{sen} \\
\text { ara a }\end{array}$ & tos, \\
\hline
\end{tabular}

\begin{tabular}{|c|c|c|c|}
\cline { 2 - 3 } \multicolumn{1}{c|}{} & $\begin{array}{c}\text { Proposta Curricular de } \\
\text { Educação de Jovens e Adultos }\end{array}$ \\
\hline $\begin{array}{c}\text { Língua } \\
\text { Portuguesa }\end{array}$ & $\begin{array}{c}\text { Estudos da Sociedade } \\
\text { e da Natureza }\end{array}$ \\
\hline
\end{tabular}

renciais de educação infantil enfatiza a construção da identidade, autonomia da criança e o seu conhecimento de mundo.

Com relação à educação de jovens e adultos, o foco das áreas de Língua Portuguesa, Matemática e dos Estudos da Sociedade e da Natureza está na preocupação com a adequação do trabalho educativo às condições de vida e trabalho dos alunos.
Os referenciais para a educação indígena, além das áreas de conhecimento, incluem temas escolhidos por um amplo grupo de professores índios, como, por exemplo, auto-sustentação, ética indígena, pluralidade cultural, direitos, lutas e movimentos, terra e preservação da biodiversidade e educação preventiva para a saúde.

Mais de um 1,4 milhão de exemplares dos Parâmetros e Referenciais Curriculares foram entregues a todos os 
professores das escolas públicas do Brasil, bem como às instituições de formação de professores. Além disso, encontros e seminários promovidos pelo MEC, secretarias de educação e universidades reuniram grandes grupos de professores e especialistas nos estados e municípios brasileiros com a finalidade de conhecer e debater esses documentos, contando ainda com inúmeros programas das televisões educativas - TV Escola e TV Executiva do MEC, TVs Educativas de diferentes estados -, que também têm ajudado na divulgação e ampliação dos debates.

Se entre 1995 e 1998 a prioridade do Ministério da Educação foi a elaboração das diretrizes curriculares, no período subseqüente, de 1999 a 2002, a prioridade é a formação de professores, o que significa repensar os cursos de formação inicial - responsabilidade das universidades - e investir em ações de formação para melhorar a prática dos professores já em exercício na sala de aula.

Para impulsionar essa discussão na comunidade educativa do país, o Ministério da Educação elaborou diretrizes para a formação de professores, seguindo os mesmos procedimentos dos documentos anteriores, já citados. Os referenciais mostram a necessidade de mudanças na formação dos professores, proporcionando o desenvolvimento de competências profissionais para atender às novas concepções da educação escolar e do papel de professor. Esses referenciais também redefinem os âmbitos do conhecimento profissional (conhecimentos sobre crianças, adolescentes, jovens e adultos, conhecimentos sobre a dimensão cultural, social e política da educação, conhecimentos pedagógicos, conhecimento experiencial contextualizado na atuação pedagógica, cultura geral e profissional) e a metodologia necessária para desenvolvêlos, além de trazerem orientações para que as escolas de formação organizem seus currículos e para que as secretarias de educação desenvolvam seus trabalhos de formação continuada.

A grande diferença entre a formação tradicional e o que se propõe nos novos referenciais é que, ao invés de ser organizada como um elenco de disciplinas, a formação de professores passe a ser definida a partir do trabalho do professor, isto é, das questões que enfrenta efetivamente na sua atuação profissional.

A partir de 1999, o MEC vem desenvolvendo em parceria com as secretarias de educação o programa "PCN em Ação". Esse programa tem como objetivo o desenvolvimento de programas de formação continuada no in- terior das escolas, incentivando o estudo em grupo dos Parâmetros e Referenciais curriculares, a troca de experiência, o trabalho em equipe; e a articulação entre a teoria e a prática pedagógica. A idéia central do programa é a de que a formação profissional deve estar relacionada ao trabalho desenvolvido na sala de aula.

O programa já está implantado em 24 estados e 960 secretarias municipais de educação, envolvendo cerca de 6.000 professores-formadores e com a meta de atingir 130.000 professores do ensino fundamental, da educação infantil e da educação de jovens e adultos.

A formação inicial de professores é de responsabilidade das universidades e teve mudanças importantes a partir da Lei de Diretrizes e Bases: uma delas é a de que a formação de professores para atuarem na educação infantil e nas séries iniciais do ensino fundamental deve ser feita em cursos de nível superior (antes era realizada em cursos de nível médio); a outra é a criação dos Institutos Superiores de Educação, que deverão ser centros formadores, disseminadores, sistematizadores e produtores do conhecimento referente ao processo de ensino, de aprendizagem e de educação escolar, com o objetivo de promover a formação geral dos futuros professores de educação básica, favorecer o conhecimento e o domínio dos conteúdos específicos ensinados nas diversas etapas da educação básica e das metodologias e tecnologias a eles associados, bem como desenvolver habilidades para a condução dos demais aspectos inerentes ao trabalho coletivo da escola.

Apesar de ainda existirem alguns professores que estão lecionando sem a devida formação exigida - os chamados professores leigos - a meta é titular esse grupo de professores por meio de formação em exercício que está sendo realizada num programa especialmente elaborado - o Proformação -, que combina parte presencial e parte a distância, com o uso de materiais impressos e de vídeos, e que se desenvolve, prioritariamente, nas regiões mais pobres do país.

O Ministério da Educação, por meio dessa reorganização curricular, visa a qualidade do ensino nas escolas públicas brasileiras, assegurando que a educação no país possa atuar de forma decisiva no processo de construção e de exercício da cidadania, sem contudo deixar de cumprir um compromisso da Nação na valorização e formação do magistério, uma vez que os docentes constituem o centro de todo o processo educacional. 